dents would be in any attempt they might fessor. Thus the pupils have derived a make to provide an efficient remedy for a twofold advantage from the secession of grievous wrong, their success would be Dr. CosoLiy-infinitely better lectures at speedy and inevitable. If, then, the phy- a very reduced fee.

sicians and surgeons be irregular in their attendance at the hospital, let the class assemble and make known their complaint by a petition addressed to the governors of the charity. Should the injury be repeated, let the students a second time assemble, and present a bold remonstrance to the aggressor. Should this extreme proceeding fail, a still more extreme measure must be resorted to-the visit of a deputation from a court of law, consisting of "John Doe and Richard Roe."

The students invariably enter to the hospitals under specific written contracts, or well-understood implied engagements. If any one of these be broken, either from wilfulness or negligence, the injured party can most unquestionably recover back in a court of law the whole amount of entrance money. Wherefore, we say to such of the lecturers as are disposed to be careless, haughty, or idle-Look to it well, comply with your obligations. When you become culprits, the pupils become your masters and your judges.

WE refer with pleasure to the introductory lecture which was delivered by Dr. Elliotson, on Monday last, in the UNIVERSTY of London. It is evidently the production of an acute observer, an able reasoner, and a bold and honest man. Besides, there is this advantage attending Dr. Elizorson's arowed principles of liberality, that he enforces practically the doctrines which he so ably inculcates theoretically.

On referring to the prospectus of lectures delivered in the University, we find with much satisfaction that Dr. Elulorson has lessened the charges of admission to each division of the course of which he is pro-

The Cholera in Paris.-Extract from a Letter from $M$. Mrorcau Jomnés, dated “Paris, Sept. 28, 1839."-_" Le nombre des décès dans les tems ordinaires a été surpassé du 24 Mars, au 1er Septembre, de 19, 723."

Professional Compliments.- (From a Correspondent.)-SIR W. Russell and Sir D. Barry have just received, through Prince Lieven, the Russian ambassador, diplomas, constituting them Hon. Members of the Imperial Academy of Medicine and Surgery of St. Petersburgh. His Majesty the Emperor had already conferred upon those gentlemen the Collar of the Order of St. Anne of Russia.

\title{
SUCCESSFUL EMPLOYMENT OF
}

\section{TRANSFUSION.}

\section{To the Editor of THE Lancet.}

SIR,-MIs.D., xtat. 50, the mother of a large family, who bad for many years been labouring under tubercular disease of the lungs, and latterly of the mesenteric glands had been very much affected. She bad been several times so ill that she appeared to be almost dying, but by treatment she survived. I was called to her again July 31 st, and found her excessively reduced from an attack of diarrboea, and finding her sinking very fast, and all stimuli lost upon her, the pulse laving left the wrist, the breathing being short and hurried, the countenance sunk, and every symptom of approaching dissolution, I determined, as the only shadow of chance, to try the effect of transfusion, an idea which 1 had for many years entertained. Accordingly on the ?nd of August, aided by my son and assistant, I carefully performed the operation. Wo found the pulse, which before was only a fluttering in the axilla, gradually return to a good beat at the wrist. The countenance was relieved, and the next day she was much better and able to take food. On the 6th I operated again on the right arm, since which she has constantly im. proved and been down-stairs. I saw her to-day about her bousehold concerns. There was not the least inflammation of the veins, or any unpleasant symptom arising from the operation. I merely state the case as it 
has turned out, leaving it to others to judge of the use that may be made of it; for my own part, under similar circumstances, $I$ should not hesitate to perform it again, but of course it must be done with great care and delicacy, or the remedy may be not so successful. I am. Sir,

Your obedient servant,

Lutterworth, Sept. 22nd, 1832.

WM. JONES.

\section{ST. BARTHOMEW'S SCHOOL.}

THE AVARICLOUS ANATOMY-FEE TAKERS.

\section{To the Edilor of TnE Lancit.}

$S_{I n},-I t$ affords me great satisfaction to observe, that some of the snug arrangements at St. Bartholomew's Hospital do at length begin to attract the attention of the Governors of that Institution, the only matter of astonishment to me is that they should have allowed so much trickery and jobbing as have hitherto been practised, and yet not have interfered. Your correspondent seems struck with the injustice of the demon. strators there doing four-fifths of the anatomical work, and yet all the profits being pocketed by Mr. Stanley, who merely comes down to give his hour's daily lecture, a very dry and uninteresting one in good truth. You have, Sir, always maintained your character as the firm and inflexible censor of jobbing, and I trust you will not allow this system to pass without the application of the instrument you so ably wield. After the death of Mr. Abernethy, it seems that the medical officers were empowered to arrange the medical school, the governors, poor easy men, thinking they put it into good hands. It is not wonderiul that Messrs. Lawrence, Stanley, and Hue, who were in possession of the field, should take especial good care to keep the good things for themselves, and they, therefore, made a capital appointment of the different classes, and were ably supported by their friends, Drs. Roberts, Latham, \&c. This, I say, considering the men, is not wonderful, but it is wonderful that men of honest intentions and honourable minds, as Mr. Vincent and Mr. Farle, that they should have supported the unjust partition, that they should sanction the gross and palpable injustice of one reaping the profits, and another doing the work; that those men, the demonstrators, instead of receiving the fair reward of their labour, should be compelled to hand over the hard-earned fees to Messrs. Lawrence and Stanley, and then (as I am informed in the case) bave 10 wait on those gentlemen for some paltry stipend. By what tenure do you think Messis.
Lawrence and Stanley hold those honours which the demonstrators Skey and Wormald do not possess? Who appointed Messrs. Skey and Wormald, but the same person who first got a signature to an infamous bond, and then appointed the signer lecturer on anatomy? Mr. Abernethy. I care not for the demonstrators individually, but I say shame on my old fellow pupils, and shame on the new ones, that they should be parties to a system so iniquitous; that they should hear first Skey, and then Wormald, explain and demonstrate all the parts of anatomy with clearness, and perspicuity, and intelligence, and after six months' daily attendance in the dissectingroom, for hours, that they, my old fellow pupils, and my recent successors, should go and pay the hard-earned fee to one who earned none of it. I say emphatically, ShaMe!

Oct. 1st.

Yours very respectfully, An Old Bartholomelv Man.

MR. STANLEY'S LECTURES.

To the Editor of 'THF Lancet.

Sin,-I should be obliged if you would insert, in the next number of your publication, the following reply to a letter in your last La NCET.

C. $\mathrm{G}$.

TO "A GOVERNOR OF ST. BARTHOLOMEW'S HOSPJTAL."

Sir,-It was with regret I observed such a signature to a letter refiecting on my much respected teacher Mr. Stanley. I will first notice the charges, and then reply to them.

That “ Mr. Stanley elsatters for three quarters of an hour, without interesting or instructing."

Its striking you as being "supremely ridiculous to suppose that his jabbering could possibly benefit the pupils."

And that "Mr. Stanley's anatomy is not of the newest."

If you would honour the theatre with your attendance, your ears would be, though not in the most agrecable manner, convinced that the full hour was expended; and, really, pity must be felt for any student who can attend Mr. Stanley's lectures without receiving valuable practical instruction. If by "jabbering," you mean speaking unintelligibly, the assertion is unfounded; for the powers of clear description may be confidently claimed for Mr. Stanley, as in this respect he is not excelled by any teacher. I believe, sir, that neither teacher nor student expects novelty in the pursuit of anatorsy, the object of the one being to impress, and of the other to 